\title{
Castleman's disease as a rare differential diagnosis of lymphadenopathy: 2 case reports and review of literature
}

\begin{abstract}
Introduction: Lymphadenopathy is a common complaint in children. It's defined as abnormality in size or character of lymph node. It may be localized or generalized. It may be part of a group of signs and symptoms or the sole finding and chief complaint. Several reasons can lead to Lymphadenopathy. Castleman's disease is a rare differential diagnosis of generalized or localized Lymphadenopathy. It's a rare lymph proliferative disorder that rarely occurs in children.
\end{abstract}

Case presentation: We reported two cases, the first one was 13years old female with multicenteric castleman's disease associated with constitutional manifestations and unusual hyaline vascular pathology successfully treated with monthly combination chemotherapy, the second one was 2.5years old male with unicentric hyaline vascular castleman's disease with unusual young age at presentation successfully treated with surgical excision.

Conclusion: Castleman's disease is a rare cause of Lymphadenopathy. Although, it's rare in children, it can occur at any age. Most of cases of multicenteric castleman's disease are plasma cell variant, yet hyaline vascular type may occur. Multicenteric castleman's disease can be successfully treated with monthly combination chemotherapy. Most cases of unicentric castleman's disease are hyaline vascular type. Although, surgical removal of unicentric type is usually sufficient to achieve complete remission, recurrence can still occur.

Keywords: lymphadenopathy, castleman's disease, hyaline vascular, plasma cell, CD
Volume 3 Issue 4 - 2015

\author{
Amany M Ali, Heba Abdel-Razik Sayed, \\ Mahmoud M Mohammed \\ Department of Pediatric Oncology, South Egypt Cancer \\ Institute, Egypt \\ Correspondence: Mahmoud M Mohammed, Department \\ of Pediatric Oncology, South Egypt Cancer Institute, Assist \\ University, Egypt, Tel: +201 | 46703 I07; \\ Email elzimbily@aun.edu.eg
}

Received: October 21, 2015 | Published: November 09, 2015
Abbreviations: HHV-8, human hepes simplex virus type 8; HIV, human immunodeficiency virus; SECI, South Egypt cancer institute; ESR, erythrocyte sedimentation rate; CRP, C-reactive protein; DNA, deoxyribonucleic acid; CT, computerized tomography; $\mathrm{LDH}$, lactate dehydrogenase; $\mathrm{CD}$, castleman's disease

\section{Introduction}

Lymphadenopathy is a common complaint in children. It's defined as abnormality in size or character of lymph node. It may be localized or generalized. It may be part of a group of signs and symptoms or the sole finding and chief complaint. Several reasons can lead to Lymphadenopathy. ${ }^{1}$ Castleman's disease (CD) is a rare differential diagnosis of generalized or localized Lymphadenopathy. It's a rare lymph proliferative disorder characterized by enlarged hyperplasic lymph nodes with vascular proliferations of uncertain cause. It's most commonly seen in adults but: it can also occur in children. ${ }^{2}$ Castleman et al first described this disorder as a benign localized enlargement of hyperplasic lymph nodes. ${ }^{3}$ Flendrig et al also described 2 separate histo-pathological types of castleman's disease on 1970. ${ }^{4}$ Historically: castleman's disease was classified according to the extent of lymph node involvement into unicentric and multicenteric types. Recently: histopathogenetic classification of castleman's disease is favored. The histopathogenetic classification distinguishes between hyaline vascular castleman's disease (HV-CD): plasma cell castleman's disease (PC-CD): mixed type: human herpes virus 8 (HHV- 8)-associated castleman's disease and multicenteric castleman's disease not otherwise specified. ${ }^{5}$

The pathology of hyaline vascular castleman's disease is characterized by lymphoid proliferation with depletion of the germinal center and expansion of the mantle zones. Small lymphocytes are arranged concentrically giving "onion-skin" appearance. ${ }^{6}$ The pathology of plasma cell type is characterized by preservation of the nodal architecture with follicular hyperplasia. Intermolecular area shows abundance of plasma cells. ${ }^{7}$ Plasma cells are usually polyclonal but may be monoclonal if it's associated with POEMS syndrome ${ }^{8}$. Human herpes virus 8 (HHV-8) associated Castleman's disease is associated with immunodeficiency. Pathologically: the involved lymph nodes are characterized by large number of immunoblasts (or plasmablasts) in the outer mantle zone of some follicles. Immunoblasts are polyclonal with weak expression of CD20 [9]. We report 2 cases of Lymphadenopathy that was diagnosed finally as castleman's disease. The first is of generalized Lymphadenopathy with constitutional manifestation diagnosed finally as castleman's disease. Patient received combination chemotherapy with long survival. The second case is of recurrent localized Lymphadenopathy diagnosed as castleman's disease with unusual very young age presentation. Surgical removal of the mass was done with long survival.

\section{Case presentation}

\section{First case}

A 13years old female child was referred to Pediatric Oncology Clinic at South Egypt Cancer Institute (SECI) as a suspected case of lymphoma with a one month history of high grade fever mainly by night associated with itching: night sweating and gradual progressive loss of body weight. Twenty days ago: she developed bilateral ankle pain and swelling not associated with trauma. Fifteen days ago: she developed puffiness of eyes: painful abdominal distention and bilateral leg swelling associated with bilateral axillary and cervical 
swellings. The child had no family or past medical history of note. Examination of the child revealed poor general condition with cachexia \{weight $=32 \mathrm{~kg}$ less than $5 \%$ of weight for age according to official 2000 center for disease controland prevention (CDC) growth charts: created by the National Center for Health Statistics\}: severe pallor: puffiness of the eyes: respiratory distress 6/10: marked decrease of air entry on the right side of chest: diffuse abdominal tenderness and rebound tenderness: positive shifting dullness with hepatomegaly about $5 \mathrm{~cm}$ below costal margin: bilateral pitting lower limb oedema and generalized painless Lymphadenopathy.

Laboratory Investigations (Table 1) revealed moderate normocytic normochromic anaemia with normal reticulocytic count: hypoalbuminemia with normal 24-hours protein collection in urine: raised acute phase reactants (Erythrocyte sedimentation rate "ESR" and C-reactive protein "CRP"): normal anti- nuclear antibody: anti double stranded DNA: rheumatoid factor and negative tuberculin test. Human immunodeficiency virus (HIV) serology was negative at presentation. Chest X-rayshowed moderate right sided pleural effusion. Computerized tomography (CT) neck: chest and abdomen showed multiple enlarged cervical lymph nodes $1.5 * 1 \mathrm{~cm}$ : enlarged bilateral axillary lymph nodes the largest one $2 * 3 \mathrm{~cm}$ : multiple enlarged anterior meditational lymph nodes $2.5 * 2.5 \mathrm{~cm}$ : moderate right sided pleural effusion: left lower lung lobe pneumonic consolidation: mild hepatomegaly and moderate free ascitis (Figure 1). Exicisional biopsy of an axillary lymph node (Figure 2) was performed and histopathological examination revealed hyaline vascular Castleman's disease ( increased number of follicles with atrophic germinal centers and the inter follicular area showing proliferation of hyalinized capillaries and thick wall blood vessels).Child received adequate supportive care and $\mathrm{CHOP}$ regimen as a combination chemotherapy \{cyclophosphamide $1000 \mathrm{mg} / \mathrm{m}^{2}$ (d1): vincristine $1.5 \mathrm{mg} / \mathrm{m}^{2}$ (d1): doxorubicin $40 \mathrm{mg} / \mathrm{m}^{2}$ (d1): prednisolone $40 \mathrm{mg} \backslash \mathrm{m}^{2}$ (d1-d5)\}. After 3 cycles of CHOP: there is marked clinical improvement with disappearance of constitutional manifestations: lower limb oedema: ascitis: pleural effusion and puffiness of the eyes.

Table I Laboratory investigations on admission to South Egypt Cancer Institute and after $6 \mathrm{CHOP}$ cycles of the $\mathrm{I}^{\text {st }}$ case

\begin{tabular}{|c|c|}
\hline On admission & $\begin{array}{l}\text { After } 6 \text { CHOP cycles (at the end of } \\
\text { treatment) }\end{array}$ \\
\hline Hemoglobin $7.8 \mathrm{~g} / \mathrm{dl}$ & Hemoglobin II \\
\hline White Cell Count $4 * 109 / 1$ & White Cell Count 3.6*109/I \\
\hline Neutrophil $25 \%$ & Neutrophil $75 \%$ \\
\hline Platelet $381 * 109 / 1$ & Platelet 249 \\
\hline ESR Ist hr $1022 \mathrm{nd}$ hr 130 & ESR Ist hr 5 \\
\hline Albumin $20 \mathrm{~g} / \mathrm{l}$ & Albumin 37g/l \\
\hline ALT 27U/I & ALT I8U/I \\
\hline AST 73U/I & AST 34U/I \\
\hline Bilirubin Total $0.19 \mathrm{mg} / \mathrm{dl}$ & Bilirubin Total 0.18 \\
\hline Urea $16 \mathrm{mg} / \mathrm{dl}$ & Urea 23mg/dl \\
\hline C-reatinin $0.5 \mathrm{mg} / \mathrm{dl}$ & C-reatinin $0.3 \mathrm{mg} / \mathrm{dl}$ \\
\hline C-reactive protein $140 \mathrm{mg} / \mathrm{l}$ & C-reactive Protein Normal \\
\hline HIV, HBV,HCV Serology -ve & \\
\hline
\end{tabular}

The child gained weight to be $36 \mathrm{~kg}$ within 4 months of treatment which correlates with the $10 \%$ of weight for age according to CDC growth charts. Laboratory investigations became free. CT neck: chest and abdomen showed bilateral enlarged deep cervical LNS largest $0.7 * 1.2 \mathrm{~cm}$ : disappearance of the previously seen right sided pleural effusion: reduction of the previously seen meditational: axillary
Lymphadenopathy to be $1 * 1.6 \mathrm{~cm}$ and disappearance of the ascitis. Child then received another 3 cycles of CHOP. On finishing treatment laboratory investigations continue to be within the normal range and CT neck: chest and abdomen revealed only bilateral nonspecific cervical lymph nodes enlargement: the largest one was $1 \mathrm{~cm}$ with disappearance of the previously described enlarged axillary and meditational lymph nodes. She is now on regular follow-up for 48 months with complete clinical and radiological remission.

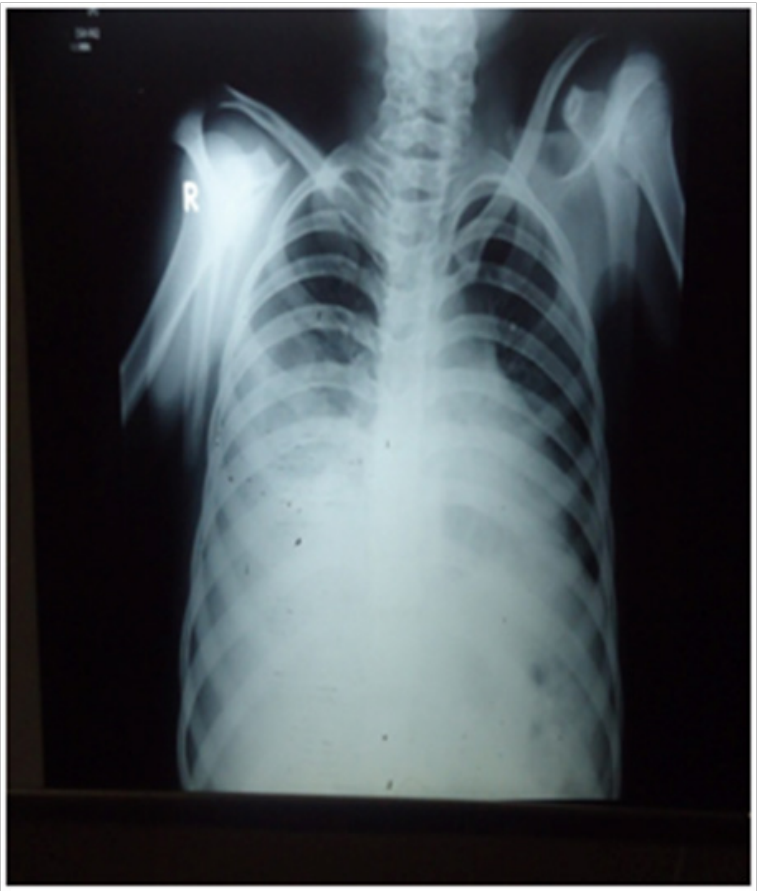

Figure I Radiological findings at presentation.

Figure Ia Chest X-ray showing moderate right sided pleural effusion.

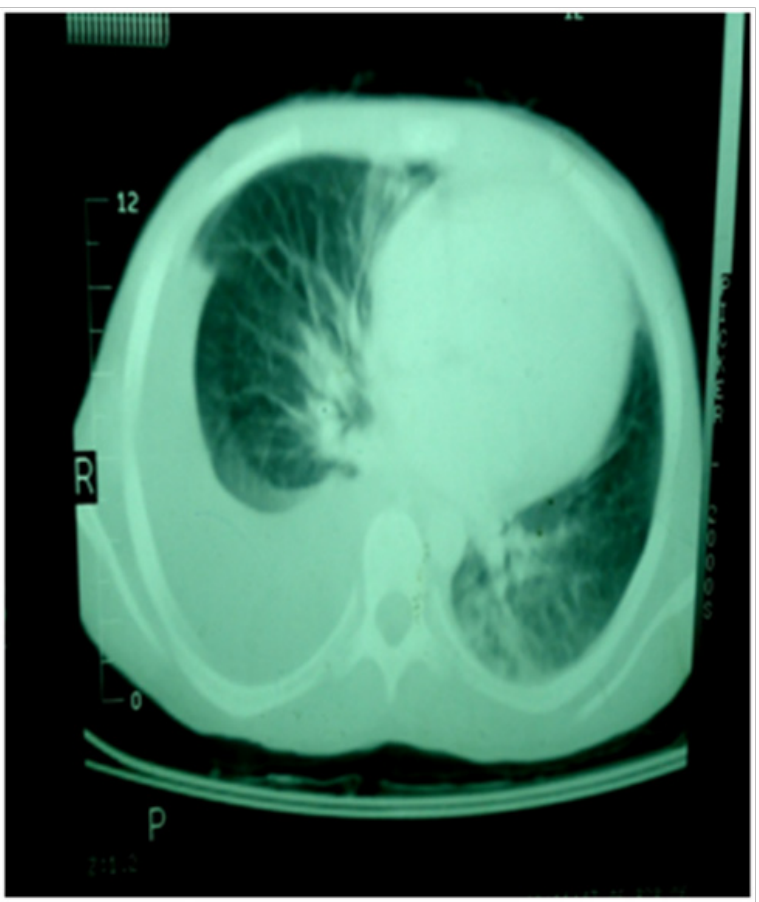

Figure IB Chest showing right sided pleural effusion. 


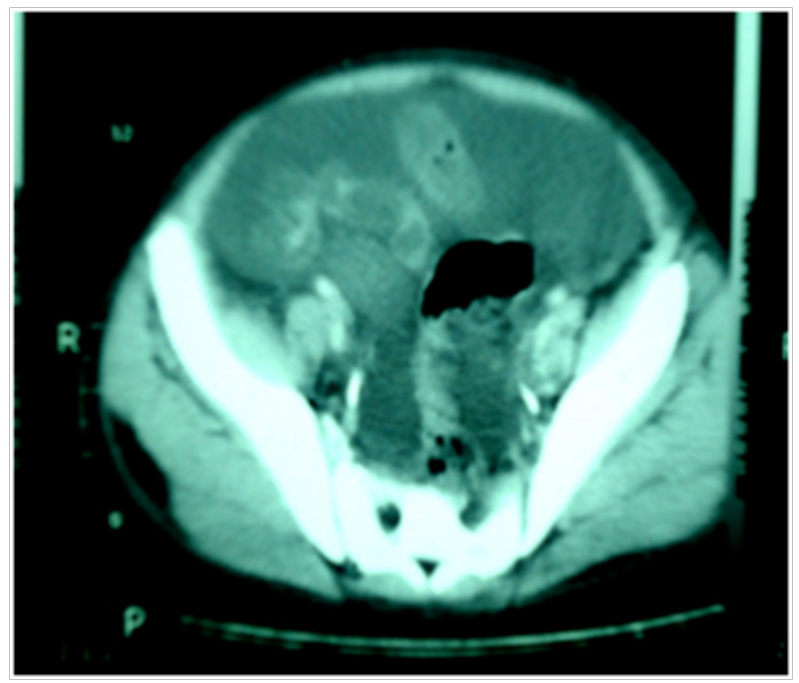

Figure IC CT abdomen showing moderate free ascitis.

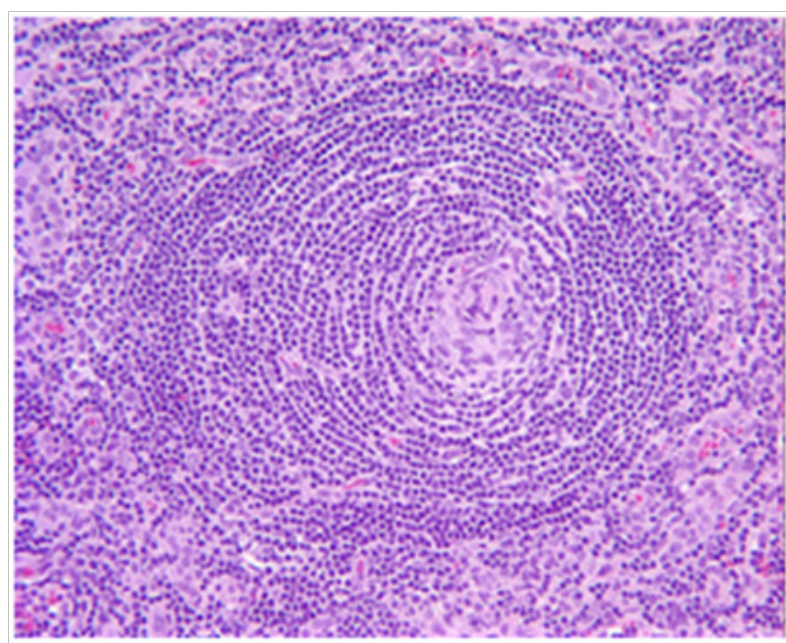

Figure 2 Histopathological picture of axillary lymph node showing hyaline vascular castleman's disease with increase number of follicles, atrophic germinal centers, the intermolecular area showing proliferation of hyalinized capillaries and thick wall blood vessels.

\section{Second case}

A 2.5years old male child was referred to Pediatric Oncology Clinic at South Egypt Cancer Institute with huge left cervical swelling. The condition started with left cervical swelling of insidious onset and progressive course so parent's saught medical advice and received medical treatment with no response then surgical removal of the swelling was done and histopathological examination revealed Castleman's disease hyaline vascular type and patient was put on follow up. At the age of 6years the child developed recurrent huge left cervical swelling not associated with trauma: fever: night sweating or itching. The child had no relevant family or past medical history. Examination of the child revealed good general condition with huge left cervical swelling occupying the upper and lower deep cervical regions about $6 * 4 \mathrm{~cm}$ with lobulated surface firm to hard in consistency mobile in all directions with normal skin overlying and no other body swellings. Laboratory investigations were normal CT neck: chest and abdomen (Figure 3) revealed multiple well defined highly vascular matted lymph node masses seen in the left cervical region causing compression and displacement of adjacent great neck vessels the largest one was $4 * 2.7 \mathrm{~cm}$ otherwise free. Complete Surgical removal of the cervical lymph nodes was done. Histopathological examination of excised lymph nodes revealed Castleman's diseases hyaline vascular type. Now patient is on regular follow up for 60 months.
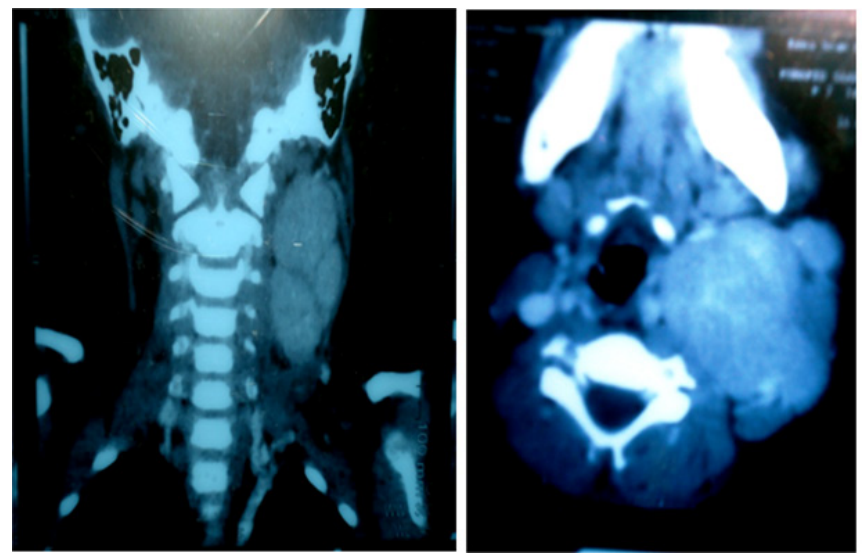

Figure $3 \mathrm{CT}$ neck showing multiple well defined highly vascular matted lymph node masses seen in the left cervical region causing compression and displacement of adjacent great neck vessels the largest one was $4 * 2.7 \mathrm{~cm}$.

\section{Discussion}

Lymphadenopathy may be localized affecting one anatomical region or generalized affecting 2 or more regions. In our case report we are presenting 2 cases of Lymphadenopathy. The first case is of generalized Lymphadenopathy with constitutional manifestations. There are large differential diagnoses of generalized Lymphadenopathy. It may result from different pathological processes as infections: autoimmune disorders: metabolic diseases and malignancy. ${ }^{10}$ Certain drugs may cause generalized Lymphadenopathy as allopurinol: phenytoin: trimehoprim/sulfamethoxazole and penicillin. Several factors should be considered during establishing a differential diagnosis to Lymphadenopathy including patient age: site: size and consistency of enlarged lymph nodes and time course of Lymphadenopathy. ${ }^{1}$

Most of the cases of generalized Lymphadenopathy in children are infectious or benign in nature. In a case series of 628 patients undergoing nodal biopsy: benign or self-limited causes were found in 79 percent of patients younger than 30years of age: versus 59 percent in patients 31 to 50years of age and 39 percent in those older than 50years. ${ }^{11}$ Patient was fully investigated to exclude infection: metabolic: autoimmune and malignant causes. Patient was finally diagnosed as multicenteric hyaline vascular castleman's disease. Multicenteric Castleman's disease is typically of the plasma cell type but in our case series the multicenteric case is of hyaline vascular type. ${ }^{12}$ Multicenteric castleman's disease is characterized by generalized Lymphadenopathy: hepatosplenomegaly and usually associated with constitutional manifestations as fever: night sweating: severe fatigue: and anorexia. Patients may suffer from peripheral oedema: ascitis and pleural effusion. Patients usually have acute phase reaction with elevated ESR: CRP: fibrinogen and thrombocytosis: while hemoglobin and albumin levels are decreased. ${ }^{13}$ Constitutional manifestations with elevated acute phase reactants in multicenteric castleman's disease are due to excessive secretion of interleukin 6 which induces a pro- inflammatory syndrome with increase secretion of vascular endothelial growth factor (VEGF) which leads to increase angiogenesis and vascularization in the involved lymph nodes. ${ }^{14}$ The second case report was a case of recurring localized 
Lymphadenopathy. Localized Lymphadenopathy represents seventy five percent of all Lymphadenopathy: with more than $50 \%$ are seen in head and neck area. ${ }^{10}$

Infection is the most common cause of cervical Lymphadenopathy which is usually acute and self limited. While most cases are self limited: some causes such as atypical mycobacterium: toxoplasmosis: cat-scratch disease: sarcoidosis: and Kawasaki's syndrome may cause Lymphadenopathy for many months: and may be mistaken with malignancy. ${ }^{15}$ Lymph node enlargement in the 2nd case was finally diagnosed as hyaline vascular castleman's disease. The second case was also presented in unusual very young age (2.5)years. Castleman's disease is a rare lymph proliferative disorder with an age range from 8years to 66years. ${ }^{12}$

Human immunodeficiency virus status is an important risk factor. Human immunodeficiency virus infected patients with multicenteric castleman's disease have much frequent plasmacytic disease and the clinical course is less favorable than in non infected patients. ${ }^{16}$ Multicenteric castleman's disease especially in human immunodeficiency infected patients may be associated with malignancies as Kaposi sarcoma: B cell lymphoma: hodgkin's lymphoma and plasmacytoma. It may also be accompanied with POEMS syndrome (polyneuropathy: organomegaly: endocrinopathy: monoclonal gammopathy: skin changes). ${ }^{17}$ Localized castleman's disease is treated by surgical excision which is curative in $90 \%-95 \%$ of cases. The prognosis is excellent with a 5years survival rate close to $100 \%{ }^{18}$ In practice diverse treatments are used for multicenteric castleman's disease: often in combination e.g.: surgery: corticosteroid and chemotherapy. Cyclophosphamide $\left(750 \mathrm{mg} / \mathrm{m}^{2}\right)$ is given in monthly pulses. Vinblastin $\left(8 \mathrm{mg} / \mathrm{m}^{2} /\right.$ week $)$ is also administered as authorized in the context of kaposi sarcoma. Monthly polychemotherapy is also an effective treatment regimen. In this context: the most effective combinations seem to be regimens like CHOP (cyclophosphamide: vincristine: doxorubicin: prednisolone) or ABVD (etoposide: ifosfamide: cisplatin alternating with doxorubicin: vinblastin: bleomycin and decarbazine). Anti-interleukin-6 antibody has also been successfully tried in the alleviation of systemic manifestations. ${ }^{19}$ Other therapies inculde intravenous immunoglobulin: anti-herpes drugs e.g. acyclovir: ganciclovir in human immunodeficiency infected patients and human herpes virus positive disease: interferon alpha ${ }^{20}$ : retinoic acid $^{21}$ and in intractable cases even autologous stem cell transplantation.

Castleman's disease is a rare cause of generalized Lymphadenopathy. Although: it's rare in children: it can occur at any age. Most of cases of multicenteric Castleman's disease are plasma cell variant: yet hyaline vascular type may occur. Multicenteric Castleman's disease can be successfully treated with monthly combination chemotherapy. Most cases of unicentric Castleman's disease are hyaline vascular type. Although: surgical removal of unicentric type is usually sufficient to achieve complete remission: recurrence can still occur.

\section{Acknowledgments}

None.

\section{Conflicts of interest}

The authors declare there is no conflict of interests.

\section{Funding}

None.

\section{References}

1. Bazemore AW, Smucker DR. Lymphadenopathy and malignancy. Am Fam Physician. 2002;66(11):2103-2110.

2. Wei BP, Taylor R, Chan YF, et al. Mesenteric Castleman's disease in childhood. ANZ J Surg. 2004;74(6):502-504.

3. Castleman B, Iverson L, Menendez VP. Localized mediastinal lymphnode hyperplasia resembling thymoma. Cancer. 1956;9(4):822-830.

4. Flendring JA. Benign giant lymphoma:Clinicopathologic correlation study. In: Clark RL, Cumly RW, editors. The Year Book of Cancer Chicago, USA:Yearbook Medical Publishers; 1970:296-299.

5. Cronin DMP, Warnke RA. Castleman disease:an update on classification and the spectrum of associated lesions. Adv Anat Pathol. 2009;16(4):236-246.

6. Williams AD, Sanchez A, Hou JS, et al. Retroperitoneal Castleman's disease:advocating a multidisciplinary approach for a rare clinical entity. World Journal of Surgical Oncology. 2014;12:30.

7. Bonekamp D, Horton KM, Hruban RH, et al. Fishman: Castleman Disease: The Great Mimic, Radio Graphics. 2011;31(6):1793-1807.

8. Al-Maghrabi J, Kamel-Reid S, Bailey D. Immunoglobulin and T-cell receptor gene rearrangement in Castleman's disease:molecular genetic analysis. Histopathology. 2006;48(3):233-238.

9. Naresh KN, Trivedi P, Horncastle D, et al. CD20 expression in the HHV-8-infected lymphoid cells in multicentric Castleman disease. Histopathology. 2009;55(3):358-359.

10. Nield LS, Kamat D. Lymphadenopathy in Children: When and how to evaluateclin pediatr (Phila). 2004;43(1):25-33.

11. Lee Y, Terry R, Lukes RJ. Lymph node biopsy for diagnosis:a statistical study. J Surg Oncol. 1980;14(1):53-60.

12. Aguilar-Rodriguez R, Milea SL, Demirci I, et al. Localized retroperitoneal Castleman's disease:a case report and review of the literature. Journal of Medical Case Reports. 2014;8:93.

13. Brian FM, Rosemary M, Mohammed A. Multicentric Castleman's disease:a case report. Journal of Medical Case Reports. 2007;1:78.

14. van Rhee F, Stone K, Szmania S, et al. Castleman disease in the $21 \mathrm{st}$ Century: an update on diagnosis, assessment, and therapy. Clin Adv Hematol Oncol. 2010;8(7):486-498.

15. Aaron L, Lidove O, Viard JP, et al. Castleman's disease in patients infected with HIV. Rev Med Interne. 2002;23(2):155-163.

16. Lang S, Kansy B. Cervical lymph node diseases in children. GMS Current Topics in Otorhinolaryngology, Head and Neck Surgery. 2014;13:08.

17. Eszes N, Tamási L, Csekeő A, et al. Unicentric mixed variant Castleman disease associated with intrabronchial plasmacytoma. Diagn Pathol. 2014;9:64.

18. Bowne WB, Lewis JJ, Flippa DA, et al. The management of unicentric and multicentric castleman's disease:A report of 16 cases and a review of the literature. Cancer. 1999;85(3):706-717.

19. Beck JT, Hsu SM, Wijdenes J, et al. Brief report:alleviation of systemic manifestations of Castleman's disease by monoclonal anti-interleukin6 antibody. N Engl J Med. 1996;330(9):602-605.

20. Pavlidis NA, Briassoulis E, Klouvas G, et al. Is interferone-alpha an active agent in castleman's disease? Ann Oncol. 1992;3(1):85-86.

21. Rieu P, Droz D, Gessain A, et al. Retinoic acid for treatment of multicentric castleman's disease. Lancet. 1999;354(9186):1262-1265. 